Egyptian Veterinary Medical Society

of Parasitology Journal

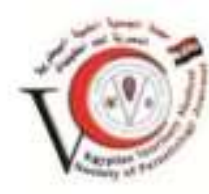

Original Article

\title{
A Review on Bovine Babesiosis in Egypt
}

Soad M. Menshawy ${ }^{1^{*}}$

,Mahmoud R. AbouLaila ${ }^{1}$, Mohamed N. Bessat ${ }^{2}$ and Noha A. Beder ${ }^{3}$

${ }^{1}$ Department of Parasitology

and ${ }^{3}$ Department of Animal

Medicine, Faculty of Veterinary

Medicine, Damanhour

University, Damanhour 22511,

El-Behera, Egypt

${ }^{2}$ Department of Parasitology,

Faculty of Veterinary

Medicine, Alexandria

University Abis 10,

Alexandria, Egypt Post Code:

21944

* Corresponding author:

soadelmenshawy@vetmed.dm

u.edu.eg

01009409039

\begin{abstract}
:
Bovine babesiosis is a tick-borne hemoprotozoan disease of cattle. It is caused by intra-erythrocytic protozoan parasites of the genus Babesia, which affects a wide range of domestic and wild animals and occasionally humans. Several species of the genus Babesia are involved, with the two most important species in cattle; are B. bigemina and B. bovis that are mainly transmitted by ticks through the transovarial route. The disease causes severe economic losses in the cattle industry, mainly associated with the reduction in the production rate and high mortalities. The disease prevails in tropical and sub-tropical areas where overlapping with the vector, one-host tick of Boophilus species, exist. Subclinical babesiosis leads to conversion of the affected livestock to chronic carriers, producing a persistent source of infection for tick vectors, and maintaining the natural transmission of the disease. Active disease cases are commonly diagnosed with the traditional geimsa-stained blood smears, although more advanced diagnosis techniques exist including, but not limited to, the molecular and serological methods. The disease is optimally controlled through treatment of affected animals, and prevention of the disease dissemination by eradicating vector ticks. This review, focused on all aspects of the disease from the historical perspectives, biology of the parasite, risk factors, pathogenesis, clinical signs, vector transmitters, diagnosis, prevention and control.
\end{abstract}

Key words: Cattle; Babesia bigemina; Babesia bovis; Epidemiology; Diagnosis

\section{INTRODUCTION}

Cattle have a great social economic importance in people life because of their milk, meat, hoof, bones and hide production (Saunsoucy 1995). Piroplasmid of the genera Babesia is a tick borne protozoa, causes a clinical fatal disease of babesiosis and associates with significant losses in the cattle and other farm animals. Thus, the disease represents serious challenges for both animal life and farm economy. Babesiosis as a tick-borne disease is widespread in tropical and sub-tropical regions which cause anemia, icterus, hemoglobinuria, and death (Wagner et al., 2002). Most affected areas are located between $40 \mathrm{xN}$ and $32 \mathrm{xS}$ (McCosker 1981). Babesia spp. is a protozoan parasite transmitted mainly by Ixodidae ticks (Silva et al., 2010) and able to infect erythrocytes of a wide variety of domestic and wild animals (El Moghazy et al., 2014). The most important species in cattle are $B$. bovis and $B$. 
bigemina (Zintl et al., 2013).

\section{2- Historical Perspective}

Victor Babes (1888) first detected a disease which caused haemoglobinuria in cattle and responsible for the death of 50 thousand cattle in Romania. He recognized them as Bacteria, giving it the naming code of Haematococcus bovis, which later changed to that of Babesia bovis (Angus 1996). In the United States, (Smith and Kilborne 1893) demonstrated the etiology of cattle Texas fever which caused by Babesia bigemina. There they also been the first to detect transmission of Babesia spp. from vector to a host by ticks of Boophilus annulatus (Smith and Kilborne 1893). Lignie'res (1903) descriped two forms of Babesia as Babesia bigemina and B. bovis in Argentina. (Hoyte 1961) recognised four species of bovine Babesia which are Babesia bovis, B. bigemina, $B$. divergens and $B$. major. It was widely concluded that $B$. bovis is highly pathogenic than B. bigemina (De Vos and Bock 2000).

\section{3- Geographical Distribution}

Babesiosis is worldwide distributed (Fakhar et al., 2012). Most affected areas are located between 40xN and 32xS where Boophilus spp. As the tick vector is commonly occurs. The main important species in cattle are $B$. bigemina and $B$. bovis that are endemic in tropical and subtropical areas. They are reported in Asia, Africa, Central and South America, Australia, and Southern Europe (Uilenberg 1995). Boophilus annulatus is the principal vector of B. bovis and B. bigemina in Turkey (Sayin et al. 1996), Northern Africa (Ndi et al., 1991, Sahibi et al., 1998 and Bouattouret al., 1999), and south Europe (Caeiro 1999). B. bovis and $B$. bigemina have the same distribution, nevertheless and in Africa B. bigemina is more prevalent than $B$. bovis because of the ability of Boophilus decoloratus and Rhipicephalus evertsi to transmit the protozoan parasite (Pohl 2013).

\section{4- Host Range}

It has been found that out of more than one hundred of Babesia spp. which infect many types of mammalian host, only 18 species cause the disease in domestic animals. Babesiosis mainly affects cattle, goats, sheep, horses, dogs, cats and human (Hamsho et al., 2015). Babesia bovis and B. bigemina are found in cattle which are the main reservoir hosts. They also affect water and African buffaloes. They were recently detected in whitetailed deer in Mexico. Animals other than cattle were considered of little epidemiological significance. (CFSPH 2008).

\section{5- Etiology and Morphology}

Babesiosis is best known as piroplasmosis, tick fever, Texas fever and Red water fever (Sahinduran 2012). The genus Babesia belongs to the phylum Apicomplexa, class Sporozoasida, order Eucoccidiorida, suborder Piroplasmorina, family Babesiidae and species $B$. bovis and $B$. bigemina (Allsopp et al., 1994). More, the phylogenetic analysis based on the 18s rRNA was used as the basis for the taxonomical classification of Babesia species (Criado-Fornelio et al., 2003). Babesia bovis is a small size parasite, located in the center of the RBCs. It measures 1-1.5 x 0.5$1.0 \mu \mathrm{m}$, and is found as pairs at an obtuse angle. While, Babesia bigemina is a much longer parasite, and found as pairs at an acute angle. Babesia bigemina is typically pear-shaped, but many irregular forms are found. It is 3-3.x 1$1.5 \mu \mathrm{m}$ (Soulsby 1986) (Fig 1, 2).

\section{6- Transmission of bovine babesiosis}

Babesia species is transmitted biologically by the tick vector via transovarian transmission which transmits from egg of mother tick (first generation) to the next stage (Demessie and Derso 2015). Bovine babesiosis is transmitted by one host tick vector (Boophilus spp.). B. bigemina and B. bovis are transmitted biologically by Boophilus 
ticks, in which nymphs and adults transmit $B$. bigemina but only tick larvae transmit $B$. bovis (Esmaeil et al., 2015). It is also transmitted mechanically by infected needles and syringes, blood transfusion and surgical instruments.

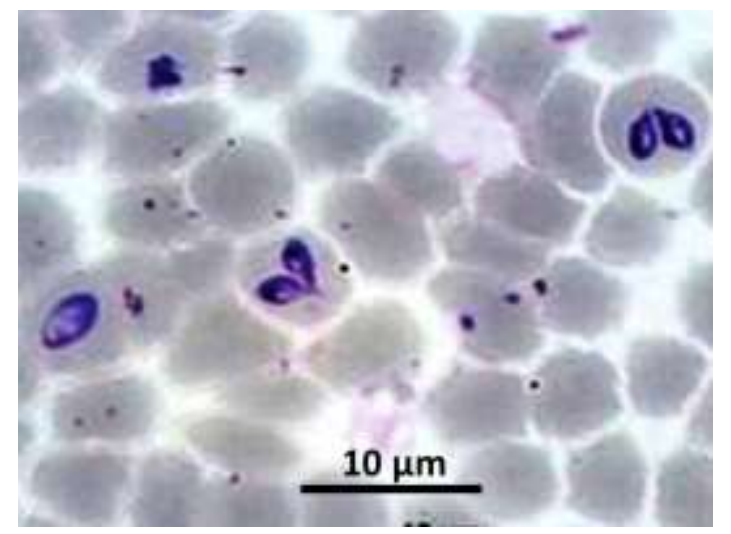

Fig (1): Giemsa stained blood smears from cattle showing Babesia bigemina, 100x. (Mosqueda et al., 2012).

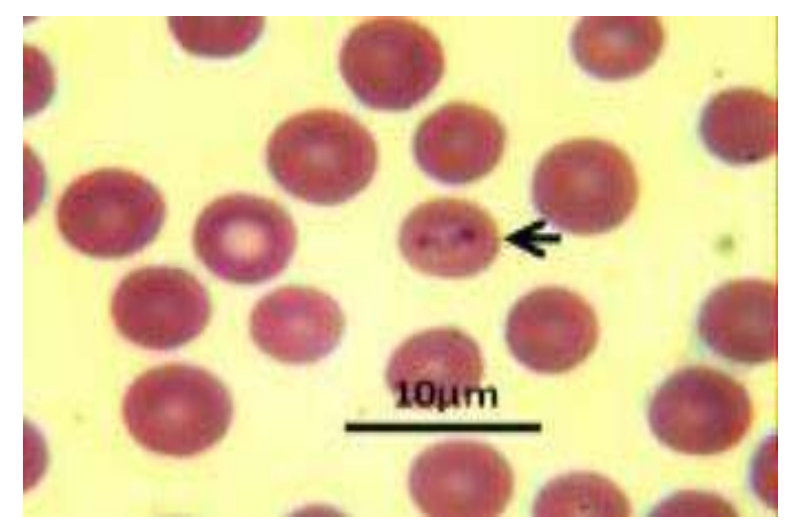

Fig. (2): Blood smear from cattle showing $B$. bovis (arrow), Giemsa stain, $100 \mathrm{x}$. (El-Bahy et al., 2018).

\section{7- Life cycle}

Life cycle of Babesia spp. divided into three stages as shown in (Plate 1, Otify 2011).

First, inside tick vector (mother tick): This stage is carried out inside the vector gut in the following way: After the ticks suck the blood of an infected animal, red blood cells break and the parasites of Babesia spp. will be released. Where most of them die, and the adult phases remain alive. The growth of both female and male gametes is completed in a period of 2-4 days after the ticks take the blood meal.
Fertilization process ended with the formation of zygote that is spherical in the beginning, then it turns into a motile form known as ookinete that begins the next stage of direct division. Ookinetes penetrate the mother tick to form large numbers of sporocysts that lead to the explosion of stomach cells, after which motile sporokinetes spread in the internal fluid (haemolymph) and various body organs, such as ovarian cells. Then the sporokinetes divide inside these tissues before and during the deposition of masses of tick's eggs. Then a new wave of division begins within the larvae after they hatch.

The second stage involves the development of the parasite within the new generations of ticks. After larvae emerge from eggs, the sporokinetes begin it's activity leading to the multiple divisions within the tissue of the larva. The larval adhesion to the animal's body begins its salivary gland in the rapid growth of salivary secretion. At this stage, sporozoites reach the cells of the salivary gland and saliva. Sporozoites penetrate the red blood cells to begin the division stage in the animal when larva takes blood meal. It is worth noting that the sporozoites do not all reach the salivary gland, but rather numbers remain in the tissue of the larva, and after the larva has molted, it turns into a nymph. In the same way, the adult tick can transmit the parasite through its eggs to new generations, and this method is repeated for several generations, which is best known as the transovarian transmission.

In the third and final stage, the development of parasite inside the host animal after being infected is concluded as follows. Sporozoites enter the animal's body with tick saliva, they begin to penetrate the red blood cells, and then turn inside them into a small circular or oval shape that has one nucleus, known as trophozoites. Asexual multiplication occurs by binary fission forming schizont. After the completion of the growth of divisions within the red blood cells, the RBCs are destructed, and then each division penetrates into 
a new red blood cell, and grows inside it in the same way as the previous, and ends with the hemolysis of the affected cells.

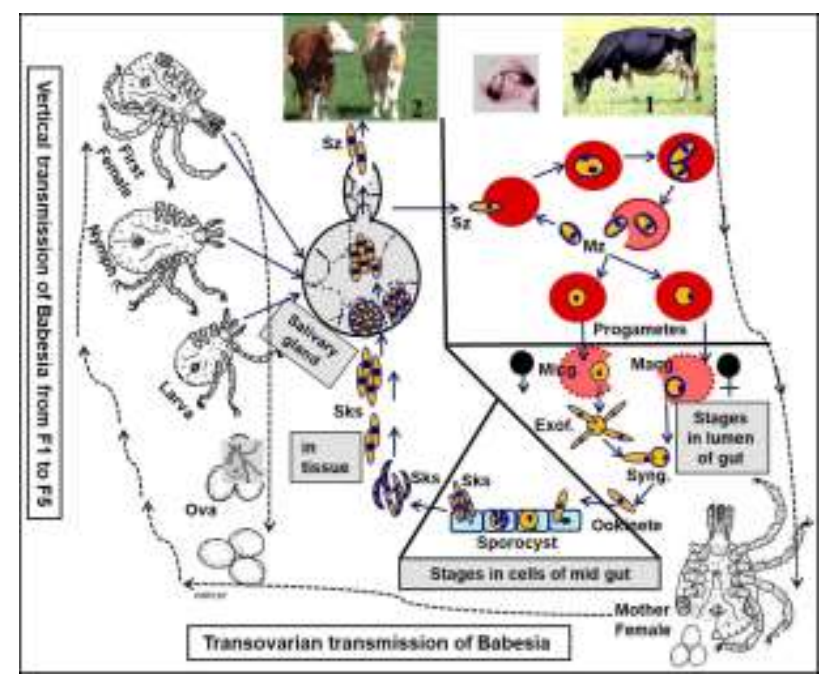

Plate. (1) A generalized life cycle for Babesia spp. in cattle and the tick vector Boophilus spp. (Otify 2011).

1 (first infected cow- donor), 2 (new infected cows- receptors), $\mathrm{Sz}$ (Sporozoite), $\mathrm{Mz}$ (Merozoite), Micg. (Microgamete), Macg. (Macrogamete), Exof. (Exoflagellation), Syng. (Syngamy), Sks (Sporokinetes), F1 (First female) and F5 (Fifth generation female).

\section{8- Vector transmitters}

Tick infestation in cattle is one of the major constraints to the livestock industry which adversely affects bovine productivity, mainly by transmission of serious pathogens (Menshawy et al., 2018). Ticks act as vectors for many protozoa as Babesia spp. which has a great hazard effect on livestock health resulting in economic impact for farmers (Hoogstraal and Kaiser 1958). Boophilus spp. especially male can transfer between cattle in close proximity and this can lead to decrease prepatent period (6-12 days) for B. bigemina (Callow and Hoyte 1961), but it is $12-18$ days after attachment of tick to animal (Callow 1984). While the larval stage only is responsible for transmission of $B$. bovis
(Mahoney \& Mirre 1979) and the prepatent period is generally 6-12 days (Callow 1984). High temperature stimulates larval tick's attachment which enables transmission of B. bovis immediately and lead to shortened prepatent periods (Dalgliesh and Stewart 1982).

\section{9- Epidemiology of the bovine babesiosis}

It depends on numbers of factors and these include:

9.1. Age of the host, the infection rate is low among young animals because of innate resistance which enhanced by maternal antibodies that transfer to calves via colostrum. This resistance is declined gradually leaving animal with high susceptibility to disease (Fadly 2012).

9.2. Breed of the host, Bos taurus breeds of cattle are more susceptible to babesiosis than Bos indicus (Radostits et al., 2007). Also, native breeds are more resistance to babesiosis than foreign breeds. Because of the nature exposure of tick populations for long time which developed either an innate resistance or an innate ability to develop a good immune response to the tick (Wodaje et al., 2019).

9.3. The immune status of the host. In endemic areas, young animals acquire immunity passively from colostrum of dam so often suffer only transient infections with mild signs. These infections are sufficient to stimulate active immunity and become carrier for long time. Active immunity is responsible for the persistence state of the carrier and premunity. These animals lose their infection either naturally or by chemotherapy but still retain a solid immunity (Taylor et al., 2007). Benavides and Sacco (2007) classified Bos taurus into three different phenotypes according to susceptibility to $B$. bovis infection as: susceptible animals which have severe clinical signs that lead to death, intermediate animals which have mild clinical signs and resistant animals which rarely 
demonstrate clinical signs.

9.4. The virulence of Babesia strain. B. bovis is more pathogenic than $B$. bigemina (CFSPH 2008). Many blood parasites survive the host immune system through rapid antigenic variation which has been demonstrated for $B$. bovis and B. bigemina (Bock et al., 2004).

9.5. Stress factors, the prevalence of babesiosis is affected by seasonal variation which also is influenced by the peak of the tick population. From the climatic factors, air and temperature is the most important because of its effect on tick activity; higher temperatures increase its occurrence (Menshawy et al., 2018). Babesia spp. infection in cattle reaches peak in the summer season (El Bahy et al., 2018).

\section{0- Clinical signs}

The clinical signs and pathogenesis vary with the age of the animal, the species and strain of the parasite. Affected animals suffered from fever which present for several days before the beginning of other clinical signs (OIE 2010), that included loss of appetite, cessation of rumination, labored breathing, emaciation, sometimes massive intravascular haemolysis which produce progressive hemolytic anemia, various degrees of jaundice (Icterus) from paleness in mild cases to severe yellow discoloration of conjunctival and vaginal mucous membranes in more progressive cases haemoglobinuria. Other signs include, accelerated heart and respiratory rates, ocular problems and drop in milk production. The fever during infections in some cases causes abortions of pregnant cattle (Abdel Aziz et al., 2014). Coffee colored urine is the characteristic clinical feature of babesiosis (De Vos and Potgieter 1994)

\section{1- Diagnosis}

Detection of active cases of babesiosis based mainly on a number of diagnostic techniques as follow:
1. Direct microscopic examination, Giemsa stained thin blood smears has been considered the traditional and golden method of identifying the agent in infected animals. It is a cheap, easily and available method in all laboratories also possibly even in the field (Nayel et al., 2012) and is a good technique for species differentiation. It is adequate for detecting cases of acute infection but less effective in low parasitemia and in carrier animals.

2. Serological examinations, Indirect fluorescent antibody test (IFAT) and enzyme linked immunosorbent assay (ELISA) are capable of detecting antibodies of Babesia in sub-clinical infections (El-Fayomy et al., 2013), and to avoid drawbacks of microscopic examination. These tests are of low sensitivity due to the occurrence of false-positive and false-negative results and cross reactions make species diagnosis difficult, and in most cases fail to differentiate between chronic and acute infections (Mahmoud et al., 2016). Nevertheless, these methods easy to do but requires a good quality antigen which is difficult to obtain (Mosqueda et al., 2012). (Anon 2008) described a complement fixation (CF) test to detect antibodies against B.bovis and B.bigemina.

3. Molecular diagnosis, polymerase chain reaction (PCR) is more sensitive and specific technique which offers an alternative approach for the detection of babesiosis (AbouLaila et al., 2010) and been able to identify the parasite in the early stage of the disease.

\section{2- Prevention and control}

Control of babesiosis is mainly based on the immunization, chemoprophylaxis and tick eradication or by a combination of these approaches (Suarez and Noh 2011). The three methods must be integrated to reach to the best results of controlling the disease and to avoid breed resistance and enzootic stability. Chemoprophylaxis is not a viable for long time, so immunization is an alternative effective method to face outbreaks of babesiosis either using live or 
dead whole parasite and isolated parasite antigen (Yusuf 2017). Cattle which recover from a primary Babesia infection or that have been immunized with attenuated parasites are resistant to challenge infection. Second, immunization of cattle with native Babesia antigen extracts or culture-derived supernatants containing secreted Babesia antigens elicit protective immunity against both homologous and heterologous challenge (Radostits et al., 2007). Animals should also be treated with an acaricide that able to prevent tick attachment especially in endemic areas. Repeated treatment of cattle with acaricides in areas of high challenge; such treatment may require to be carried out twice weekly in order to kill the tick before the infective sporozoite develop in the salivary gland (Urquhart et al., 1996). In endemic areas, where all indigenous cattle are infected as calves, no control is usually necessary. Maintenance of the enzootically stable state is dependent on exposure of calves to the infection while they are most resistant. If the challenge is still sporadic, continual vaccination of the calf crop from year to year may be necessary (El Sawalhy2012). Reduced tick numbers will decrease time risk of babesiosis due to the reduced natural exposure of animals. Affected animal should be treated as soon as possible with a suitable treatment to control babesiosis in some areas of the world (Kuttler 1981). The indiscriminate use of antiBabesia prophylactic agents including the administration of the drug at sub lethal blood levels to animals, can produce the development of drug resistant parasites, a problem that will require the development of new drugs (Vial and Gorenflot 2006).

\section{3- Economic importance}

Recently Babesia becomes the most widespread parasite due to exposure of 400 million cattle to infection through the world (Osman and Gaadee 2013). Bovine babesiosis impairs cattle improvement programs due to their imposing significant economic burden on meat and milk production beside to costs of treatment and tick control. It is currently considered as the most important endemic parasitic disease affecting cattle in Egypt (Adham et al., 2009). Babesiosis, especially in cattle has great economic importance, because unlike many other parasitic diseases, it affects adults more severely than young cattle, leading to direct losses through death and the restriction of movement of animals by quarantine laws (Onoja et al., 2013). The consequence is that the quality of cattle in endemic areas remains low, therefore impeding the development of the cattle industry and the wellbeing of producers and their families (Mosqueda et al., 2012).

\section{4- Status of bovine babesiosis in Egypt}

Bovine piroplasmids are endemic in Egypt and widespread in other regions of the world including the Mediterranean Basin (Ibrahim et al., 2009). The variable infection rates of babesiosis among cattle in Egypt have been reported by numbers of studies such as: Ezzat (1960) found that B.bigemina was the most common blood parasite in cattle in Assuite governorate. Mohan (1968) found that $15 \%$ of the buffaloes and $20 \%$ of cattle infected with B. bigemina in Egypt. .El- Allawy (1973) stated that the incidence of B. bigemina in cattle was from 7.05 to $10.66 \%$ by using blood films examinations in Assuit governorate.

Sakla (1975) reported that 8.6 of buffaloes and 8.7 of cattle infected with B.bigemina on examination stained blood samples, in Assuit governorate, Egypt. Ahmed (1980) recorded that the rate of infection of B. bigemina was 8.5 in cattle in Sharkia governorate.

Gattase (1983) found that the rate of cattle infection with B. bigemina were $25.5 \%$ and $27.77 \%$ in Port Said and Ismailia respectively. While El- Bahy (1986) stated that $38 \%$ of cattle 
were infected with $B$. bigemina, in Fayoum governorate. Chafick (1987) reported that the incidence of Babesia spp., in calves over one year old was $4.97 \%$ and calves over two years old was $10.89 \%$ in Assuit governorate. ElSawalhy (1987) recorded that $4.5 \%$ of native cattle breed and $8.6 \%$ of foreign cattle breed were positive for $B$. bigemina in Qalyobia governorate. Abo El-Kheir (1989) observed a wide variation in the incidence of B.bigemina in cattle as 2.89, 4.46, 5 and 10.17\% in Giza, Beni Suef, El- Minyia and Fayoum governorates, respectively. Gattase (1990) recorded that the incidence of Babesia spp., was $7.62 \%$ in cattle using ELISA in Suez Canal Zone. Abd ElGawad (1993) observed that the incidence of B. bigemina and B. bovis in cattle was 8.62 and $1.65 \%$ respectively in Beni Suef governorate. El-Ghaysh (1993) found that the incidence of B. bigemina in Cairo, Delta and Upper Egypt was $12.5,4$ and $5.7 \%$ in cattle respectively. While the incidence of $B$. bovis was $13.5,8$ and $8.6 \%$ in cattle in the same region respectively. Ashmawy et al., (1998) investigated $B$. bigemina infection in a local breed of cattle with Giemsa-stained blood films. Prevalence was higher in Hoosh-Easa (67.8\%) and Shubrakheit $(25 \%)$ followed by Damanhour (37\%) and Itay Elbaroud (17.8\%) in Behaira Province. Salem (1999) recorded that the incidence of Babesia bigemina in cattle was $40.9 \%$, while the incidence of B. bovis was $30 \%$ as measured by PCR technique. While by microscopic examination only $1.8 \%$ was detected in Giza governorate. Adham et al., (2009) found that the prevalence of B. bovis and B. bigemina in Boophilus annulatus ticks were 55 and $66 \%$, respectively. Also, presence of $12 \%$ dual infection with $B$. bovis and $B$. bigemina was observed in Egypt. Ibrahim et al., (2009) examined cattle for the presence of piroplasm, the results discovered the majority of Babesia spp., infection (26\%), most of them infected by B. bigemina (17\%) in Egypt. Mervat et al., (2010) detected B. bigemina in cattle in $38 \%$ by Giemsa stained blood smears in Qalyobia Governorate. Fadly (2012) showed that the incidence of Babesia spp. in cattle by blood film examination were $19.33 \%$ at Behaira province. Nayel et al., (2012) found that the prevalence of Babesia spp. was $8.15 \%$ by direct microscopy using Giemsa-stained thin blood smears in Menofia. Moreover, Ibrahim et al., (2013) recorded the prevalence of $B$. bigemina and $B$. bovis from cattle by nPCR were 5.30 and $3.97 \%$ respectively in Behaira and Fayoum provinces. EI Moghazy et al., (2014) revealed that the infection rate with blood films examination was $22.47 \%$ in Qalyobia Governorate. Elsify et al., (2015) found cattle infection with $B$. bovis and B. bigemina, 3.18 and.97\% using PCR assays in Egypt. The seroprevalence of protozoan infections in cattle in Qena and Sohag governorate, Upper Egypt was determined with enzyme-linked immunosorbent assays using species-specific diagnostic antigens as reported by Fereig et al. (2017) in his study, they found that $33.2 \%$ and $42.2 \%$ of examined cattle were found to be positive for specific antibodies against $\mathrm{B}$. bovis and B. bigemina, respectively. El-Bahy et al., (2018) found the infection with Babesia spp. was $9.42 \%$ in Behaira. Cattle management, climatic condition, immune status, tick distribution, breeds, and the sampling condition might explain the variation in prevalence rates between previous studies in Egypt.

\section{5- Methods of control of bovine babesiosis in} Egypt

Control of babesiosis is mainly based on the chemotherapy and tick eradication in Egypt. Imidocarb dipropionate salt (Imizol) is effective for babesiosis. Diminazene aceturate (Berenil) is widely used. Supportive therapy such as vitamins, electrolytes and hematinic drugs and blood transfusion may be essential if the animal is to survive (Mohammed and Elshahawy 2017). The 
most effective procedure for the control of babesiosis is to eradicate its vector, the Boophilus tick by dipping all cattle once a week (El Sawalhy 2012). It has to be taken into consideration that cattle management, the proper use of acaricides and frequency of application of acaricides as more than six applications per year will create a risk for the development of resistant ticks (Aboelhadid et al., 2018).

\section{6- References}

Abdel Aziz, K. B., Khalil, W. K. B., Mahmoud, M. S., Hassan, N. H. A. and Mabrouk, D. M. (2014): Molecular characterization of babesiosis infected cattle: Improvement of diagnosis and profiling of the immune response genes expression. Global Veterinaria, 12(2): 197-206.

Abd El-Gawad, M. (1993): Some studies on Babesia species in cattle in Beni-Suef Governorate. Ph.D. Thesis, Fac. of Vet. Med. Cairo Univ.

Aboelhadid, S.M., Waleed M. Arafa , Lilian N. Mahrous, Magdy M. Fahmy, Asmaa A. Kamel. (2018): Molecular detection of Rhipicephalus (Boophilus) annulatus resistance against deltamethrin in middle Egypt. Vet. Parasitol: Regional Studies and Reports, 13:198-204.

Abo El-Kheir, E. A. (1989): Epidemiological aspects on the distribution of haemo-tropic parasites among cattle in Upper Egypt confirmed by the identification of en-countered organisms. M.V. Sci. Thesis, Fac. of Vet. Med. Cairo Univ.

AbouLaila, M., Yokoyama, N. and Igarashi, I. (2010): Development and evaluation of two nested PCR assays for the detection of Babesia bovis from cattle blood. Vet Parasitol, 172:6570 .

Adham, F. K., Abd-el-Samie, E.M., Gabre,
R. $M$ and El-Hussein, H. (2009): Detection of tick blood parasites in Egypt using PCR assay IBabesia bovis and Babesia bigemina. Parasitol Res 105(3): 721-730.

Ahmed, A. B. (1980): some biological studies on blood parasites of farm animals. Ph.D. Thesis. Fac. of Vet. Med. Zagazig Univ.

Allsopp, M., Cavalier-Smith, T., De Waal, D. and Allsopp, B. (1994): Phylogeny and evolution of the piroplasms. Parasitology, 108: 147-152.

Angus, B. (1996): The history of the cattle tick Boophilus microplus in Australia and achievements in its control. International J. of Parasitology, 26: 1341-1355.

Anon (2008): The center for food security and public health of bovine babesiosis.

Ashmawy, K. E; El-Wafa, S. A. A. and Fadly, R. S. (1998): Incidence of Babesia bigemina infection in native breed cattle, Behera Province, Egypt using different methods of diagnosis. Assiut Vet. Med. J. 39(77): 110-120

Babes, V. (1888): Sur l'hemoglobinurie bacterienne $\mathrm{du}$ boeuf. Comptes rendus hebdomadaires des seances de l'Academie des Sciences, Paris 107: 692-694.

Benavides M.V. and Sacco A.M. (2007): Differential Bostaurus cattle response to Babesia bovis infection, Vet. Parasitol. 150:54-64.

Bock, R., Jakson, L., De Vos, A. and Jorgensen, W. (2004): Babesiosis of cattle. Parasitology, 129: 247-269. DOI: 10.1017/S0031182004005190

Bouattour, A., Darghouth, M. A. and Daoud, A. (1999): Distribution and ecology of ticks (Acari: Ixodidae) infesting livestock in Tunisia: an overview of eight years field collections. Parassitologia 41 (1): S5-S10.

Caeiro, V. (1999): General review of tick species present in Portugal. Parassitologia 41: 11-15.

Callow, L. L. (1984): Piroplasms. In Animal Health in Australia, Protozoal and Rickettsial 
Diseases, 5: 121-160. Canberra,Australian Bureau of Animal Health, AGPS.

Callow, L. L. and Hoyte, H.M. D. (1961): Transmission experiments using Babesia bigemina, Theileria mutans, Borrelia sp. and the tick cattle Boophilus microplus. Aust. Vet. J. 37: 381-390.

Center for Food Security and Public Health (CFSPH). (2008): Bovine babesiosis, Iowa state university, Ames, Iowa.

Chafick, M. L. (1987): Serological tests for the field diagnosis of Babesia infection in calves. M. V. Sc. Thesis, Fac. of Vet. Med. Cairo Univ.

Criado-Fornelio, A., Martinez- Marcos, A., Bulingsarana, A. and Barba- Carretero, J. (2003): Molecular studies on Babesia, Theileria and Hepatozoon in southern Europe. Part II. Phylogenetic analysis and evolutionary history. Vet. Parasitol. 114: 173-194.

Dalgliesh, R. J. and Stewart, N. P. (1982): Some effects of time, temperature and feeding on infection rates with Babesia bovis and Babesia bigemina in Boophilus microplus larvae. International J. for Parasitol, 12: 323326.

Demessie, Y. and Derso, S. (2015): Tick Borne Hemoparasitic Diseases of Ruminants: A Review. Adv. in Biological. Res. 9: 210-224.

De Vos, A. and Bock, R. (2000): Vaccination against bovine babesiosis and anaplamosis. acadamic science, 916: 540-545.

De Vos, A.J. and Potgieter, F. T. (1994): Bovine babesiosis. In: Coetzer JAW, et al. (Eds.), Infectious diseases of livestock. Oxford University Press, Cape Town, USA: 278-294.

El-Allawy, T. A. (1973): Some studies on bovine piroplasmosis in Assiut. M.V.Sci. Thesis, Fac. of Vet. Med. Assiut Univ.

El-Bahy, N. M. (1986): Some studies on tick borne disease among ruminants in Fayoum
Gogernorate. M.V. Sci. Thesis. Fac. of Vet. Med. Cairo Univ.

El-Bahy, N. M., Menshawy, S. M., Goda, W. M., Nasr, S. M., AbouLaila, M. R. Bazh, E. K. and Abou-Rwash, A. A. (2018): Molecular detection of Babesia bigemina and Babesia bovis in cattle in Behaira Governorate.ejpmr. 5(12): 441-446.

El-Fayomy, A. O., Ghoneim, A. M., AbuSamak, O. A. and Khidr, A. A. (2013): Contribution of Babesia to the illness of cows in Port Said Governorate, Egypt. Global Veterinaria, 11 (1): 118-122.

El-Ghaysh, A. A (1993): Studies on Babesia species infecting cattle and water buffaloes in Egypt. Ph. D. Thesis, Parasitology, Fac. Vet. Med, Cairo Univ.

El Moghazy, H. M., Ebied, M.H., Abdelwahab, M. G. and El-Sayed, A. A. (2014): Epidemiological studies on bovine babesiosis and Theileriosis in Qalubia Governorate. Benha Vet. Med. J. 27(1):36-48.

El-Sawalhy, A. (1987): Some studies on cattle blood parasites in Kalubia Province M.V.Sc .Thesis. Infectious diseases, Fac. of Vet. Med. Zagazig University.

El-Sawalhy, A. (2012): Veterinary infectious diseases in domestic animals. $3^{\text {rd }}$ Edition: Ahram Distribution Agency, Egypt.

Elsify, A .; Sivakumar, T.; Nayel, M.; Salama, A.; Elkhtam, A.; Rizk, M.; Mosaab, O.; Sultan, K.; Elsayed, S.; Igarashi, I. and Yokoyama, N. (2015): An epidemiological survey of bovine Babesia and Theileria parasites in cattle, buffaloes, and sheep in Egypt. Parasitol Int. 64(1):79-85.

Esmaeil, N., Tavassoli, M., Asri-Rezaei, S., Dalir- Naghadeh, B. and Mardani, (2015): Determination of prevalence and risk factors of infection with babesia ovis in small ruminants from west Azerbaijan province, Iran by 
Polymerase chain reaction. J. Arth. -Borne Dis. 9: 246-252.

Ezzat, M. A. E. (1960): The geographical distribution and incidence of important parasitic diseases in Egypt and its bearing on the livestock production. J. Egypt. Vet. Med. Assoc. 20(2):127-136.

Fadly, R. S. (2012): Prevalence of some blood parasites of some farm animals at Behera Province. Assiut Vet. Med. J. 58 (134):316-322.

Fakhar, M., Hajihasani, A., Maroufi, S., Alizadeh, H., Shirzad (2012): An epidemiological survey on bovine and ovine Babesiosis in Kurdistan Province, western Iran. Trop. Anim. Health and Production, 44: 319322.

Fereig, R. M., Mohamed, S.G, Mahmoud, H.Y., AbouLaila, M. R. and Guswanto, A. (2017): Seroprevalence of Babesia Bovis Babesia. Bigemina,Trypanosoma evansi and Anaplasma marginale antibodies in cattle in southern Egypt. Ticks Tick Borne Dis 8(1): 125-131.

Gattase, M. W. (1983): Some studies on cattle Babesiosis in Suez Canal Zone. Master Thesis, Fac. of Vet. Med. Cairo Univ.

Gattase, M. W. (1990): Further studies on the biological aspects of Babesia species in Suez Canal Zone with special reference to their control. PhD, Thesis, Fac. of Vet. Med. Cairo Univ.

Hamsho, A., Tesfamarym, G. and Megersa, M. (2015): A Cross-Sectional Study of Bovine Babesiosis in Teltele District, Borena Zone, South.ern Ethiopia. J. of Vet. Sci. and tech., Health Production, 29: 11-15.

Hoogstraal, H. and Kaiser, M. N. (1958): Observation on Egyptian Hyalomma ticks (Icodoidea: Ixodidea). 1. Parasitism of Iosards by nymph. Ana. Ent. Soc. Amer. 51(1): 7-12.

Hoyte, H. M. (1961): Initial development of infectious Babesia bigemina. Australian Vet. J. 8: $462-466$.

Ibrahim, A.k.; EL Behairy, A.M.; Mahran K.A. and Awad,W.S. (2009): Clinical and laboratory diagnosis of piroplasmids in naturally infected cattle in Egypt. J. Egypt.Vet. Med. Assoc. 69 (2): 105-203

Ibrahim, H. M.; Adjou Moumouni, P. F.; Mohammed-Geba, K.; Sheir, SK.; Hashem, I. S.; Cao, S.; Terkawi, M. A.; Kamyingkird, K.; Nishikawa, Y.; Suzuki, H. and Xuan, X. (2013): Molecular and serological prevalence of Babesia bigemina and Babesia bovis in cattle and water buffalos under small-scale dairy farming in Beheira and Faiyum Provinces, Egypt. Vet Parasitol. 198(1-2):187-92.

Kuttler, K. L. (1981): Chemotherapy of babesiosis: A review. In Babesiosis. 65- 85.

Lignie 'res, J. (1903): Bovine babesiosis. New investigations and observations on the multiplicity, the evolution and natural transmission of the parasites involved in the disease and on vaccination. Archives de Parasitologie, 7: 398-407.

Mahmoud, M. M., EI Diasty, M. M., Rasheed, N. M., Kheder, Z. and Rehab, R. A. (2016): Molecular detection of babesia infection in young calves in Damietta governorate, Egypt. Glob. Anim. Sci. J. 4(2): 185-193.

Mahoney, D. F. and Mirre, G. B. (1979): A note on the transmission of Babesia bovis (syn. B. argentina) by the one-host tick, Boophilus microplus. Research in Vet. Sci. 2: 253-254.

McCosker, P. J. (1981): The global importance of babesiosis. In Babesiosis (ed. Ristic, M. and Kreier, J. P.): 1-24. New York, Academic Press.

Menshawy, S. M., Bazh, E. K. and AbouRawash, A. A. (2018): Dynamics of Boophilus Ticks and its Role in Transmission of Piroplasms at Behaira District. AJVS. 56 (1): 137-144.

Mervat, E. I. Rdwan.; Ola, F. A. Talkhan and 
Ali. M.A. (2010): Cattle Babesiosis and associated biochemical alterations in Kalubyia Governorate. Nature and Science, 8(3): 29-36.

Mohammed, E. S. and Elshahawy, I. (2017): The Current Prevalence of Bovine Babesiosis and Theileriosis Infection in Egypt. Clin. Med. Images. Int. J. 1(1): 00004.

Mohan, R. N. (1968): Diseases and parasites of buffaloes (Review article). Ref. Vet. Bull. Abst. : 4405-4852.

Mosqueda, J., Olvera, R., Aguilar, T. and Cantó, G. (2012): Current Advances in Detection and Treatment of Babesiosis. Current Med. Chem. 19: 1504-1518.

Nayel, M., El-Dakhly, K. M., Aboulaila, M., Elsify, A., Hassan, H., Ibrahim, E., Salama, A. and Yanai, T. (2012): The use of different diagnostic tools for Babe-sia and Theileria parasites in cattle in Menofia, Egypt. Parasitol Res. DOI 10.1007/s00436-012-2926-6.

Ndi, C., Bayemi, P. H., Ekue, F. N. and Tarounga, B. (1991): Preliminary observations on ticks and tick-borne diseases in the North West province of Cameroon. I. Babesiosis and anaplasmosis. Revue D'Elevage ET De Medecine Veterinaire Des Pays Tropicaux 44, 263-265.

OIE (2010): Bovine babesiosis chapter 2 at http;//web.oie.int/eng/norms/mmanual/2008/ pdf/ /2. 04.

Onoja, I. I., Malachy, P., Mshelia, W.P., Okaiyeto, S.O., Danbirni, S. and Kwanashie, G. (2013): Prevalence of Babesiosis in cattle and goats at Zaria Abattoir, Nigeria. J. of Vet. Adv. 3: 211-214.

Osman, F.A. and Gaadee, H.I. M. (2013): Evaluation of antioxidant response mechanism in fattening cattle calves suffering from Babesiosis in New Valley Governorate. Egypt. J. of Vet. Adv. 3: 232-237.

Otify, Y. Z. (2011): Veterinary Parasitology
(Arabic language), 2nd ed. Publish. Soot ElKalam El-Araby,

Egypt. WWW.Alsooot.com/booksmall

Pohl, A. (2013): Epidemiology study of tickborne diseases in cattle in Minas Gerais. J. of Vet. Adv., 40:124-150.

Radostits, O., Gay, G., Hinchiff, K. and Constable, P. (2007): Veterinary Medicine: A text book of the disease of cattle, sheep, goat, pigs and horses. $10^{\text {th }}$ edition London: Saunders Elsevier, PP: 1110-1489.

Sahibi, H., Rhalem, A., Berrag, B. and Goff, W. L. (1998): Bovine babesiosis. Seroprevalence and ticks associated with cattle from two different regions of Morocco. Annals of the New York Academy of Sciences 849: 213-218.

Sahinduran, S. (2012): Protozoan diseases in farm ruminants. In A Bird's Eye View of Veterinary Medicine. Perez Marin, C. (Ed). Inernational J. Tech. 473-477

Sakla, A. A. (1975): Studies on ticks in Assiut Governorate, with special reference to their role in transmission of parasitic diseases. Ph. D. Thesis, Fac. of Vet. Med. Assiut Univ., Egypt.

Salem, G.H. (1999): Diagnosis of both Babesia bovis and Babesia bigemina infections among carrier cattle by using extra -chromosomal DNA based Polymerase Chain Reaction test in Egypt. Assuit. Vet. Med .J. 42(83): 38-50.

Saunsoucy, R. (1995): Livestock-a driving force for food security and sustainable development. World Animal Review, 84(85): 5-17.

Sayin, F., Dincer, S., Karaer, Z., Cakmak, A., Inci, A., Yukari, B. A., Eren, H., Friedhoff, K. T. and Muller, I. (1996): Studies on seroprevalence of Babesia infection of cattle in Turkey. In Acta Parasitologica Turcica, Proceedings of the VIII International Congress of Parasitology - New Dimensions in Parasitology, 20 (1) (ed. O* zcel, M. A.): 505-516. Izmir, Turkish Soci. for Parasitol. 
Silva, M. G., Marques, P.X. and Oliva, A. Urquhart, G. M., Armour, J., Duncan, J. L., (2010): Detection of Babesia and Theileria Dunn, A.M. and Jennings, F.W. (1996): species infection in cattle from Portugal using a Veterinary Parasitology. 2nd ed. USA: Blackwell reverse line blotting method. Vet Parasitol Science Incorporated. 242-253.

174(3-4): 199-205.

Smith, T. and Kilborne, F. L. (1893): Investigations into the nature, causation and prevention of Southern cattle fever. In Ninth Annual Report of the Bureau of Animal Industry for the Year 1892, 177-304. Washington, Government Printing Office.

Soulsby, E. J. (1986): Helminths, Arthropods and Protozoa of Domesticated Animals. (7th edn), Bailliere Tindall, London, UK.

Suarez, C.E. and Noh, S. (2011): Emerging perspectives in the research of bovine

Babesiosis and Anaplasmosis. Vet. Parasitol. 180: 109-125.

Vial, H J. and Gorenflot, A. (2006): Chemotherapy against babesiosis. Vet. Parasitol. 138: $147-160$.

Wagner, G. G., Holman, P., and Waghela, S. (2002): Babesiosis and heat water: threats without boundaries. The Veterinary Clinics of North America Food Animal Practice 18(3): 417-430.

Wodaje, A.; Biyansa Adudna and Hamid, M. (2019): A Review on Bovine Babesiosis. Int. J. Adv. Res. Biol. Sci. 6 (1): 63-70.

Yusuf, J. J. (2017): Review on Bovine Babesiosis and Its Economical Importance. Austin J Vet Sci and Anim Husb. 4(2): 1035.

Taylor, M., Coop, R. and Wall, R. (2007): Zintl, A., Mulcahy, G., Skerrett, H., Taylor, S. Veterinary Parasitology. 3rd ed. Blackwell Publishing, USA. PP: 103-115.

and Gray, J. (2013): Babesia divergens, a bovine blood parasite of veterinary and zoonotic importance. Clinical microbiology reviews, 16:

Uilenberg, G. (1995): International 622-636.

collaborative research: significance of tickborne hemoparasitic diseases to world animal health. Vet. Parasitol. 57: 19-41. 
Menshawy et al..

EVMPSJ 2020,16: 8-19 